\title{
Historical Bibliography in the Digital World
}

\section{Anne Welsh}

Lecturer in Library and Information Studies http://www.ucl.ac.uk/dis/people/annewelsh @AnneWelsh

Acting Director of Studies UCL Department of Information Studies http://www.ucl.ac.uk/dis/

Digital Identity Manager UCL Centre for Digital Humanities http://www.ucl.ac.uk/dh/

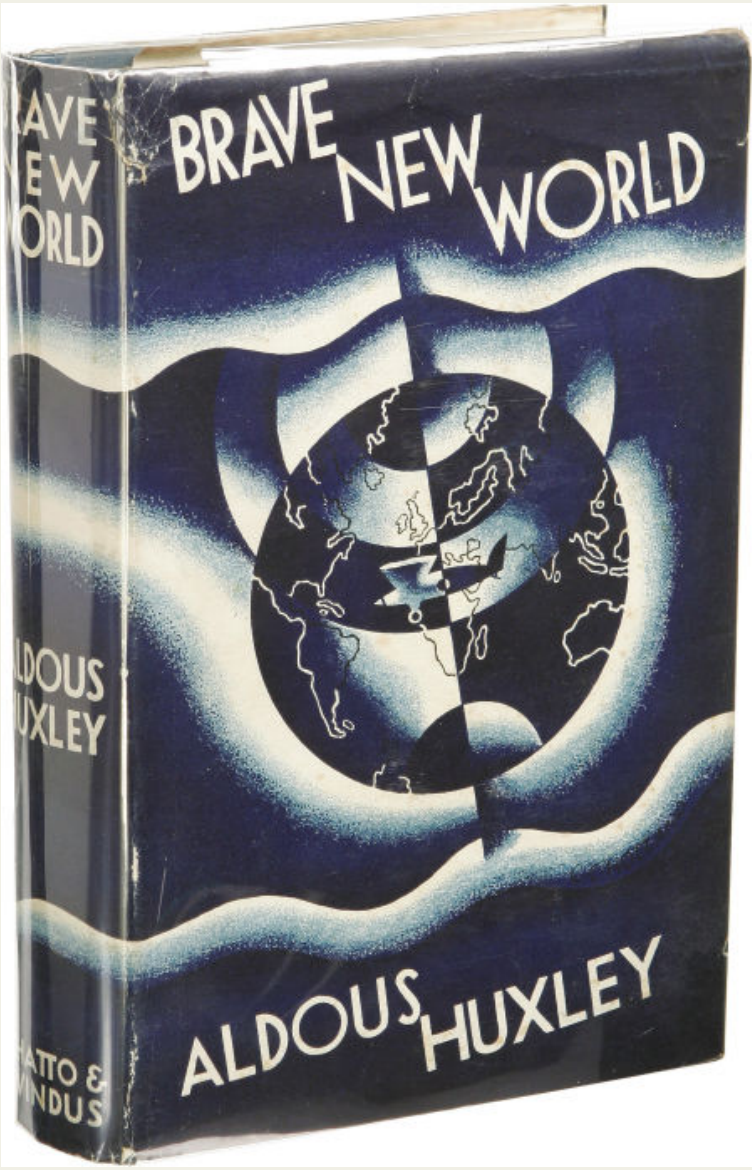




\section{"Flat" Bibliographic Initiatives}

- These examples convey bibliographic information via the web, but do not capitalise on the opportunities of the internet age:

- English Book Owners in the $17^{\text {th }}$ Century

- John Dee's Library Catalogue. Additions and Corrections.

- London Book Trades Database 


\section{Evolution}

- This has evolved from a printed source

- Cathedral Libraries Catalogue

- to an online database

- CLCi database

- which is also included in larger databases

- CERL Heritage of the Printed Book (HPB)

$-\underline{\text { COPAC }}$ 


\section{British Library Initiatives (selected)}

- All these not only provide a starting point for research, but embody traditional bibliographic scholarship within digital "containers":

- Incunabula Short Title Catalogue

- English Short Title Catalogue

- British National Bibliography

- BNB in RDF/XML (CCO 1.0 license)

- British Library Bindings Database 


\section{Watermarks: a Case Study}

- Wasserzeichen des Mittelalters (WZMA)

- Watermarks in Incunabula in the Low

Countries (WILC)

- Piccard Online

- Bernstein: the Memory of Paper 

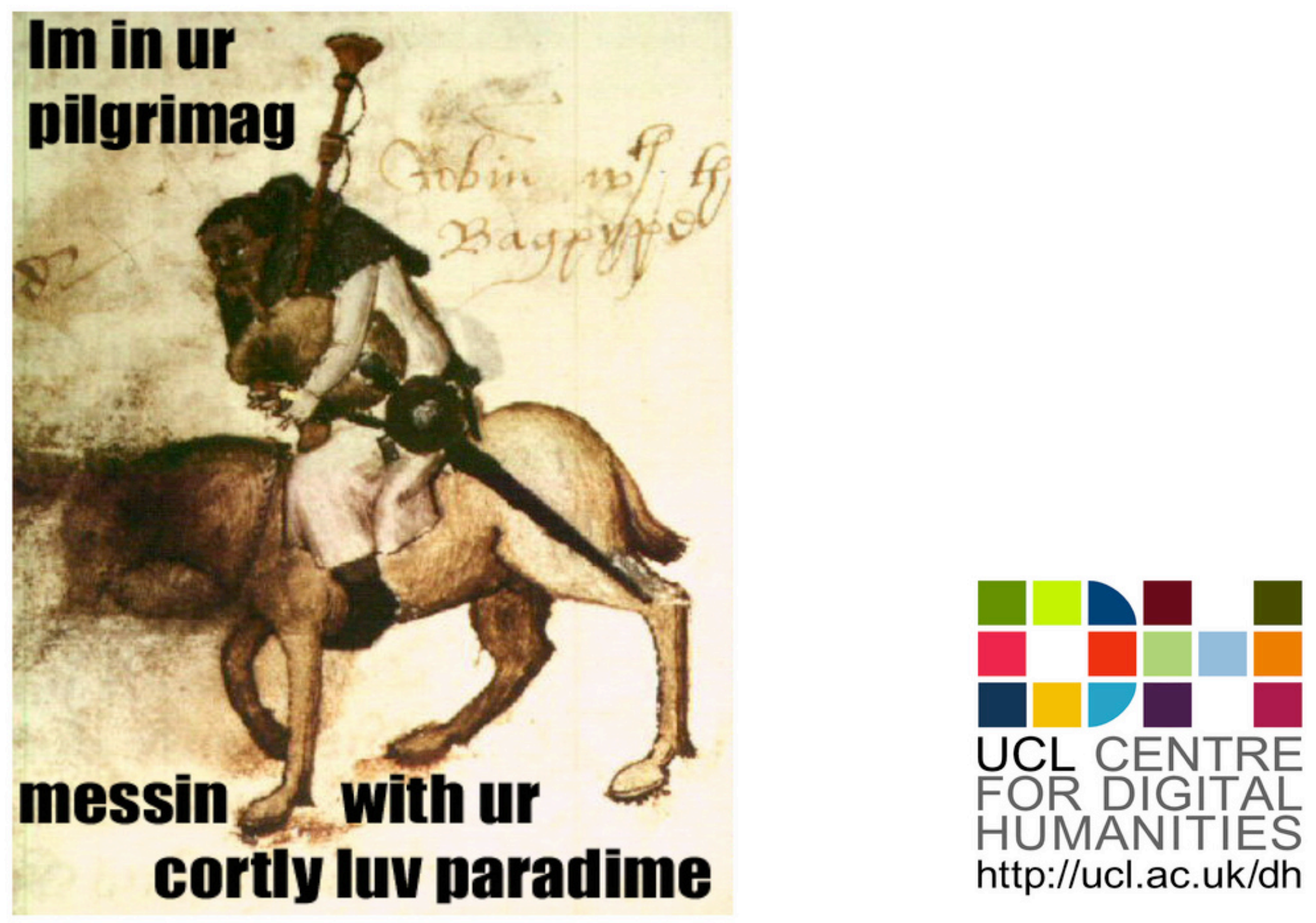